\title{
Applicability of Liquid Chromatography with Time-of-Flight Mass Spectrometric Detection for Determination of Cyanuric Acid in Soil ${ }^{\dagger}$
}

\author{
Sanja Stipičević, ${ }^{a}$ Gordana Mendaš, ${ }^{a}$ Marko Vuletić, ${ }^{b, \ddagger}$ Sanja Fingler, ${ }^{a}$ and Vlasta Drevenkar ${ }^{a, *}$ \\ ${ }^{a}$ Institute for Medical Research and Occupational Health, Ksaverska c. 2, Zagreb, HR-10000, Croatia \\ ${ }^{\mathrm{b}}$ PLIVA-Research \& Development Ltd., Prilaz baruna Filipovića 25, Zagreb, HR-10000, Croatia
}

RECEIVED JUNE 20, 2012; REVISED JANUARY 29, 2013; ACCEPTED FEBRUARY 7, 2013

\begin{abstract}
Cyanuric acid (2,4,6-trihydroxy-1,3,5-triazine, CA) is a highly polar and hydrophilic degradation product of symmetric triazine herbicides, fairly stable under environmental conditions. We investigated the applicability of reversed-phase liquid chromatography coupled to time-of-flight mass spectrometry (LC-ToF-MS) for qualitative and quantitative determination of CA in soils of different origin and pedological characteristics. CA was ultrasonically extracted from soils either with a mixture of acetone and $n$-hexane (volume ratio $=2: 1$ ) or with methanol and analysed on a LiChrospher $100 \mathrm{CN}$ column with $\psi($ acetonitrile,water $)=50: 50$ as the mobile phase for isocratic elution. The efficiency and selectivity of LC-ToF-MS determination, using the electrospray ionisation in negative mode and selective monitoring of deprotonated CA molecule $(\mathrm{m} / \mathrm{z} 128)$, was evaluated with respect to injection volume, extracting solvent, and possible soil matrix interferences. The advantage of LC-ToF-MS over conventional HPLC with UVdiode array detection was the high ion detection selectivity minimising the interferences of coeluting species and the unambiguous identification of CA in soil extracts by accurate mass measurements of deprotonated molecule. (doi: 10.5562/cca2109)
\end{abstract}

Keywords: cyanuric acid, soil, liquid chromatography, time-of-flight mass spectrometry, soil matrix interferences

\section{INTRODUCTION}

Cyanuric acid (2,4,6-trihydroxy-1,3,5-triazine, CA) is a highly polar, hydrophilic compound, fairly stable under many environmental conditions. In solution, it occurs as a mixture of keto (isocyanuric acid) and enol tautomers, the latter form being stable under alkaline conditions $(\mathrm{pH}>7.2)$ (Figure 1). ${ }^{1}$

$\mathrm{CA}$ is an industrial chemical whose derivatives are widely used as disinfectants, sanitizers, and bleaches (chloroisocyanurates), cross-linking and curing agents (triallyl and tris(hydroxyethyl) isocyanurates), ingredients of weather resistant powder coatings (tris(epoxypropyl)isocyanurate), and fire retardants in plastics (melamine cyanurate) ${ }^{2} \mathrm{CA}$ is used to stabilize the chlorine disinfectant in swimming pools because it is able to form $\mathrm{N}$-chlorinated isocyanurates and prevent the rapid photolytic degradation of residual chlorine. CA is also a by-product of melamine (2,4,6-triamino-1,3,5-triazine) production, another industrial chemical, and one of the melamine microbial metabolites. ${ }^{3}$ In the recent years, both compounds have attracted remarkable attention as potentially harmful adulterants deliberately incorporated in pet food, animal feed, and human food (including infant formula, milk, and milk products). Their role in the mentioned foodstuffs was to increase the calculated apparent protein level by increasing the food total nitrogen content. ${ }^{4}$ When combined, CA and melamine can form crystals of insoluble melamine cyanurate via hydrogen bonding, whose deposition in kidneys leads to renal failure. ${ }^{4-6}$

In water and soil, CA can be regarded as a marker of symmetric triazine herbicide's degradation because<smiles></smiles>

Figure 1. Structure of enol (cyanuric acid) and keto (isocyanuric acid) tautomers.

\footnotetext{
$\dagger$ This article belongs to the Special Issue devoted to the $85^{\text {th }}$ anniversary of Croatica Chemica Acta.

* Present address: Hospira Zagreb d.o.o., Prilaz baruna Filipovića 27/D, Zagreb HR-10000, Croatia

* Author to whom correspondence should be addressed. (E-mail: vdreven@imi.hr)
} 
it is the ultimate hydroxylated metabolite in their degradation pathway to ring cleavage. CA is formed by microbial degradation, ${ }^{7-10}$ chemical oxidation, ${ }^{11}$ and photooxidation $^{12,13}$ of parent triazine compounds. Héquet et al. ${ }^{12}$ demonstrated an efficient degradation of atrazine, the best known member of the group of triazine herbicides, during photolysis in a photoreactor or a photocatalytic system with titanium dioxide and a reduced range of irradiation. The main degradation pathway was dehalogenation with $\mathrm{CA}$ as the ultimate product. Adding $\mathrm{H}_{2} \mathrm{O}_{2}$ to the photocatalytic system significantly enhanced the atrazine degradation. This procedure, integrated with microbial degradation of the formed CA, led to the complete degradation and detoxification of atrazine. ${ }^{13}$ Degradation of atrazine partly depended on its reactivity with soil minerals. ${ }^{14}$ The major products of atrazine degradation on birnessite (delta- $\mathrm{MnO}_{2}$ ), a common soil component, were hydroxylated and mono- and didealkylated atrazine, but ammeline (4,6-diamino-2-hydroxy-1,3,5-triazine) and CA were also detected.

Analytical methods developed for the determination of CA in different environmental, biological, and food matrices mostly employ the high-performance liquid chromatography (HPLC) coupled with UV or mass spectrometric (MS) detection. The HPLC-UV methods using the modified silica or porous graphitic carbon columns, phosphate buffer eluents, and UV detection at wavelengths of $200 \mathrm{~nm}$ to $220 \mathrm{~nm}$ have been developed for determining CA in water, ${ }^{1,15,16}$ cereal flours, ${ }^{17}$ pet food, ${ }^{18}$ and animal feed samples. ${ }^{19}$ The UV-detection has also been applied for the determination of free $\mathrm{CA}$ in nylon by ion-exclusion chromatography. ${ }^{20}$ However, due to the coeluting interferences absorbing UV light below $220 \mathrm{~nm}$, UV detection of CA is often not sufficiently selective. Most of the recent studies dealing with the determination of CA have used different modes of the more selective MS detection allowing an unambiguous identification and more accurate quantification of target analyte. Liquid chromatography coupled with mass spectrometry (LC-MS) ${ }^{21}$ or tandem mass spectrometry using the triple quadrupole mass analysers (LC-MS/MS) has been employed as a sensitive technique for determination of $\mathrm{CA}$ residues in pet food ${ }^{22}$ and infant formula samples, ${ }^{23}$ fish and shrimp tissues, ${ }^{24}$ kidney tissue, ${ }^{25}$ and human urine. ${ }^{21,26} \mathrm{CA}$ was detected using the electrospray ionisation ${ }^{21-24,26}$ or atmospheric pressure chemical ionisation ${ }^{25}$ in negative ion mode.

Gas chromatographic (GC) methods that have been reported for the determination of $\mathrm{CA}$ in different matrices are based on its conversion to a more volatile derivative. Capillary GC coupled with flame thermionic specific detection and MS detection of methylated CA has been applied for CA determination in swimming pool water, surface water, simulated air filter samples, and human urine. ${ }^{27} \mathrm{CA}$ silyl derivatives have been used for GC-MS determination of CA in extracts of animal feed $^{28}$ and GC-MS/MS determination in extracts of milk and milk products. ${ }^{29}$

There are also several mass spectrometric methods developed for direct determination of $\mathrm{CA}$ without a previous chromatographic separation step. CA extracted from water has been determined by stable association complex electrospray mass spectrometry using a solid probe technique. ${ }^{30}$ Matrix-assisted laser desorption ionisation/Time-of-flight mass spectrometry (MALDI/ToF-MS) has been demonstrated as a potential screening technique for the determination of melamine and related compounds including $\mathrm{CA}$ in biological matrices. ${ }^{31} \mathrm{~A}$ fast semi-automated method employing direct analysis in real time (DART) ion source coupled to ToF-MS has been developed for the determination of melamine and CA in milk powder and milk based products. $^{32}$ Besides mass spectrometry methods, a surface enhanced Raman spectroscopy (SERS) method has also been tested for detection and quantification of melamin and CA extracted from milk. ${ }^{33}$

The literature reviewed has shown that analytical methods developed so far for the determination of CA mostly focus on food and feed matrices, swimming pool water, and biological samples such as kidney tissue and human urine. To the best of our knowledge, at this time no method has been proposed for the determination of $\mathrm{CA}$ in soil where it can occur as a degradation product of symmetric triazine herbicides. As a highly water soluble compound, CA involves a high risk of leaching from the soil into the surface and ground waters. The aim of this study was to test the applicability of the ToF-MS to the LC determination of CA in extracts of soils/sediments of different origin and pedological characteristics. The potential of this technique for analysing different pesticides and their polar metabolites in water and complex food matrices was extensively described and discussed in two recently published reviews. ${ }^{34,35}$ In this paper, we evaluated the efficiency and selectivity of LC-ToF-MS determination of CA in soil/sediment extracts with respect to extracting solvent and possible soil/sediment matrix interferences. We also reported the mass fractions of CA found in industrial soils that were long contaminated with triazine herbicides.

\section{EXPERIMENTAL}

\section{Chemicals}

Cyanuric acid anhydrous ( $\geq 98 \%$ ) was purchased from Fluka (Buchs, Switzerland). Chlorotriazine herbicides atrazine (6-chloro- $N^{2}$-ethyl- $N^{4}$-isopropyl-1,3,5-triazine2,4-diamine), simazine (6-chloro- $N^{2}, N^{4}$-diethyl-1,3,5- 
triazine-2,4-diamine), propazine (6-chloro- $N^{2}, N^{4}$-diisopropyl-1,3,5-triazine-2,4-diamine), and terbuthylazine (6-chloro- $N^{2}$ - tert - butyl- $N^{4}$ - ethyl-1,3,5 - triazine-2,4-diamine), all of $\geq 99 \%$ purity, were from Riedel de Haën (Seelze, Germany). Formic acid min. $98 \%$, p.a., LiChrosolv acetonitrile gradient grade for liquid chromatography and SupraSolv acetone, methanol, and $n$-hexane for gas chromatography, were supplied by Merck KGaA (Darmstadt, Germany). Leucin enkephalin synthetic, $98 \%$, was purchased from Sigma-Aldrich (St. Louis, USA). All other chemicals were products of analytical reagent grade of Kemika (Zagreb, Croatia). LC-grade water was prepared by purifying distilled water with a Milli-Q water purification system from Millipore (Bedford, MA, USA).

\section{Soil Samples}

Four top-layered industrial soil samples, Ind Soil 1-4, were collected in an agrochemical factory at the locations exposed to repeated spills of effluent from atrazine synthesis. Industrial soils were stored at $4{ }^{\circ} \mathrm{C}$ and analysed for $\mathrm{CA}$ and triazine herbicides within 24 hours after sampling without previous drying and sieving.

Forest surface soil, Forest Soil $(0 \mathrm{~cm}$ to $20 \mathrm{~cm})$, was sampled in a park located in the residential area of the city of Zagreb. Agricultural surface soil, Agr Soil $(0 \mathrm{~cm}$ to $25 \mathrm{~cm})$, and three subsurface sediments: $A g r$ Sed $1(25 \mathrm{~cm}$ to $55 \mathrm{~cm}), A g r$ Sed $2(30 \mathrm{~cm}$ to $50 \mathrm{~cm})$, and $A g r$ Sed $3(22 \mathrm{~cm}$ to $50 \mathrm{~cm})$ were collected in an agricultural area of north-east Croatia. For the method development experiments, all soil and sediment samples were air-dried at room temperature and sieved through a $1-\mathrm{mm}$ sieve. The $\mathrm{pH}$ of soil/sediment samples was measured in the supernatant after overnight equilibration of $0.5 \mathrm{~g}$ air-dried samples with $3 \mathrm{~mL}$ of deionized water. The characteristics of forest and agricultural soil/sediments are shown in Table 1.

\section{LC Determination of Cyanuric Acid}

The HPLC-UV determination of CA was performed on a Varian liquid chromatograph (Varian, Walnut Creek, CA, USA) equipped with a Varian ProStar 230 SDM pump, Varian ProStar 410 autosampler employing a $100 \mu \mathrm{L}$ sample loop, and a Varian ProStar 330 photodiode-array detector (DAD). The UV spectra were record- ed from $200 \mathrm{~nm}$ to $300 \mathrm{~nm}$ and the working wavelength was $213 \mathrm{~nm}$. One chromatographic column was Hypersil ODS (Thermo Hypersil-Keystone LLC, Bellefonte, PA, USA) and the other was LiChrospher $100 \mathrm{CN}$ (Merck, Darmstadt, Germany); both were $250 \mathrm{~mm} \times 4.6 \mathrm{~mm}$ i.d. and of $5 \mu \mathrm{m}$ particle size. The isocratic elution was carried out either with $\psi($ acetonitrile,water $)=5: 95$ or $50: 50$, or with $\psi$ (acetonitrile, $0.01 \mathrm{~mol} \mathrm{~L}^{-1}$ phosphate buffer $\mathrm{pH}=$ $7.2)=5: 95$ mobile phase at a flow-rate of $1 \mathrm{~mL} \mathrm{~min}^{-1}$.

For the LC-ToF-MS determination of CA, a Waters LC system (Waters, Milford, MA, USA) was coupled with a Micromass quadrupole-time of flight mass spectrometer, Q-TOF Micro, equipped with a lock-spray option (Micromass, Manchester, UK). The LC system was built-up of a Waters 2795 autosampler and pump and a Waters 2996 photodiode-array detector. The column was LiChrospher $100 \mathrm{CN}, 250 \mathrm{~mm} \times 4.6 \mathrm{~mm}$ i.d., of $5 \mu \mathrm{m}$ particle size (Merck, Darmstadt, Germany). The column temperature was $30{ }^{\circ} \mathrm{C}$. The $\mathrm{CA}$ water solutions were injected into a $1 \mathrm{~mL} \min ^{-1}$ flow of $\psi($ acetonitrile, water $)=50: 50$ used as the mobile phase for isocratic elution. CA was detected in the negative electrospray ionisation (ESI) mode under the following conditions: capillary voltage $2800 \mathrm{~V}$, sample cone voltage $50 \mathrm{~V}$, extraction cone voltage $1 \mathrm{~V}$, ion energy $2 \mathrm{~V}$, multichannel plates (MCP) detector $2700 \mathrm{~V}$, desolvation temperature $150{ }^{\circ} \mathrm{C}$, source temperature $80^{\circ} \mathrm{C}$, cone gas flow $0 \mathrm{~L} \mathrm{~min}^{-1}$, desolvation gas flow $550 \mathrm{~L} \mathrm{~min}^{-1}$, collision energy 10 V. Lock-spray: scan frequency was $5 \mathrm{~s}$ and cone voltage $50 \mathrm{~V}$. Leucine enkephalin was used as a reference mass. Calibration was performed using a calibration mixture of $10 \%$-formic acid, $0.1 \mathrm{~mol} \mathrm{~L}^{-1}$ sodium hydroxide, and acetonitrile in the volume ratio $1: 1: 8$. The mass spectra were acquired by scanning over a mass range of $\mathrm{m} / \mathrm{z} 80$ to $\mathrm{m} / \mathrm{z} 600$. CA was detected, identified and quantitated using the extracted ion chromatograms for the target ion of deprotonated molecule $(\mathrm{m} / \mathrm{z} 128)$.

Prior to the LC-MS analysis, all samples were filtrated through $0.45 \mu \mathrm{m}$ PTFE filters (Waters, Milford, MA, USA).

\section{GC Determination of Triazine Herbicides}

Triazine herbicides extracted from industrial soils were analysed on a Varian Star 3400Cx gas chromatograph (Varian, Walnut Creek, CA, USA) with a septum-

Table 1. Pedological properties of soils and sediments

\begin{tabular}{cccccc}
\hline Sample & $\mathrm{pH}($ water $)$ & Organic matter $/ \%$ & Clay $/ \%$ & Silt $/ \%$ & Sand $/ \%$ \\
\hline Forest Soil & 3.93 & 4.6 & 12.4 & 31.0 & 56.6 \\
Agr Soil & 4.70 & 1.9 & 23.2 & 25.8 & 51.0 \\
Agr Sed 1 & 5.34 & 4.1 & 53.0 & 26.2 & 20.8 \\
Agr Sed 2 & 7.74 & 1.6 & 23.0 & 29.8 & 47.2 \\
Agr Sed 3 & 6.60 & 1.6 & 22.6 & 31.2 & 46.2 \\
\hline
\end{tabular}


equipped programmable injector (SPI) and a thermionic sensitive detector (TSD). The GC column was a Supelco SPB-1701 fused silica capillary column (Supelco, Bellefonte, PA, USA), $30 \mathrm{~m} \times 0.25 \mathrm{~mm}$ i.d., film thickness $0.25 \mu \mathrm{m}$. The column temperature was programmed from $90{ }^{\circ} \mathrm{C}$ (with $1 \mathrm{~min}$ hold) up to $200{ }^{\circ} \mathrm{C}$ at $15{ }^{\circ} \mathrm{C}$ $\mathrm{min}^{-1}$, and then up to $220{ }^{\circ} \mathrm{C}$ at $2{ }^{\circ} \mathrm{C} \min ^{-1}$; the total run time was $18 \mathrm{~min}$. The injector temperature was programmed from $110{ }^{\circ} \mathrm{C}$ (with hold of $0.1 \mathrm{~min}$ ) up to $270{ }^{\circ} \mathrm{C}$ at $200{ }^{\circ} \mathrm{C} \mathrm{min}{ }^{-1}$ with a hold of $3 \mathrm{~min}$. Detector temperature was $300{ }^{\circ} \mathrm{C}$. Carrier gas was helium with a flow rate of $1.2 \mathrm{~mL} \mathrm{~min}^{-1}$. Detector hydrogen, air,

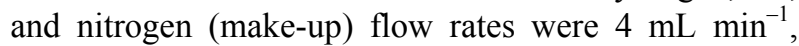
$175 \mathrm{~mL} \mathrm{~min}^{-1}$, and $28 \mathrm{~mL} \mathrm{~min}^{-1}$, respectively. Helium (purity $>99.9999 \%$ ), air (purity $>99.999 \%$ ), and nitrogen (purity $>99.999 \%$ ) were supplied by SIAD Spa (Bergamo, Italy). Hydrogen was produced with the Parker ChromGas Hydrogen Generator 9150 (Parker Hannifin Corporation, Haverhill, MA, USA). The injected sample volume was $1 \mu \mathrm{L}$.

The identity of triazine herbicides extracted from industrial soils was confirmed by analysing soil extracts on a Varian Saturn II GC-MS system, which consisted of a Varian 3400 gas chromatograph fitted with SPI and ion trap detector (ITD). The samples were analysed on an Rtx-5MS column (Restek, Bellefonte, PA, USA) under the same conditions as described earlier. ${ }^{36}$

\section{Standard Solutions of Cyanuric Acid and Triazine Herbicides}

Two stock standard solutions of cyanuric acid were prepared: a $1 \mathrm{~g} \mathrm{~L}^{-1}$ in ethanol and a $400 \mathrm{mg} \mathrm{L}^{-1}$ in LCgrade water. Aqueous stock solution was sonicated to facilitate dissolution of CA. For spiking the soil/sediment samples, stock solutions were further diluted with acetone or methanol. The CA standards for HPLC$\mathrm{UV}(\mathrm{DAD})$ and LC-ToF-MS determination were prepared by diluting the aqueous stock solution with 0.01 mol L $\mathrm{L}^{-1}$ phosphate buffer $\mathrm{pH}=7.2$ and LC-grade water, respectively.

Acetonic stock solutions of $1 \mathrm{~g} \mathrm{~L}^{-1}$ of triazine herbicides were diluted with ethyl acetate to prepare the standards for gas chromatographic determination of compounds extracted from industrial soils.

\section{Determination of Triazine Herbicides and Cyanuric Acid in Industrial Soils}

Ultrasonic extraction of triazine herbicides and CA from industrial soils was based on a procedure described and discussed earlier. ${ }^{36}$ Briefly, a 5 g portion of wet industrial soil (Ind Soil 1-4) was sonicated with $20 \mathrm{~mL}$ of $\psi($ acetone, $n$-hexane $)=2: 1$ mixture for $5 \mathrm{~min}$. After being centrifuged at $425 \mathrm{~g}$, the supernatant was decanted and the extraction was repeated with a new $10 \mathrm{~mL}$ portion of the same solvent mixture. For the GC determination of triazine herbicides, the combined extracts were evaporated under a stream of nitrogen to the water residue $(\approx 0.2 \mathrm{~mL})$. After adding anhydrous sodium sulphate $(\approx 0.2 \mathrm{~g})$, the mixture was extracted twice by vortexing the sample with $1 \mathrm{~mL}$ of ethyl acetate for $1 \mathrm{~min}$. The extracts were combined and reduced under a stream of nitrogen to $1.0 \mathrm{~mL}$. To minimize the solventmatrix effect on the GC detector response to triazine herbicides, the matrix-matched standards were prepared by adding increasing volumes of a standard mixture of triazine compounds in acetone to $5 \mathrm{~mL}$ aliquots of blank extract of Forest Soil. ${ }^{36}$

For the LC determination of cyanuric acid, industrial soil samples were extracted with $\psi($ acetone, $n$-hexane $)=$ 2: 1 mixture as described above. The extract was evaporated to dryness under a stream of nitrogen and the residue was redissolved in $1.0 \mathrm{~mL}$ of $0.01 \mathrm{~mol} \mathrm{~L}^{-1}$ phosphate buffer, $\mathrm{pH}=7.2$, for the HPLC-UV(DAD) determination or in $1.0 \mathrm{~mL}$ of LC-grade water for the LC-ToF-MS determination.

For calculating the mass fractions of triazine compounds on a dry mass basis, soil moisture content was determined by weighing $5 \mathrm{~g}$ portions of each industrial soil before and after drying at $100^{\circ} \mathrm{C}$ for $\approx 3$ hours, i.e. until reaching the constant mass.

\section{Extraction Recovery of Cyanuric Acid from Soil/sediment}

The extraction recovery of CA from dry soil/sediment was tested by spiking the air-dried and sieved Forest Soil and Agr Sed 3 with CA at $15.3 \mathrm{mg} \mathrm{kg}^{-1}$ level. The samples $(3 \mathrm{~g})$ were moistened with $1 \mathrm{~mL}$ of acetone and then spiked with $1.0 \mathrm{~mL}$ of $45.8 \mathrm{mg} \mathrm{L}^{-1}$ methanolic solution of CA. The samples were made homogeneous by manual shaking and then left at room temperature for 24 hours for the solvent to evaporate. The spiked soils/sediments underwent ultrasonic extraction first with $15 \mathrm{~mL}$, and then with another $10 \mathrm{~mL}$ of methanol or mixture of acetone and $n$-hexane (volume ratio $=2: 1$ ) following the procedure described for determination of CA in industrial soils. For the LC-ToF-MS determination, dry residues that remained after evaporation of Forest Soil and Agr Sed 3 extracts were dissolved in 1.0 $\mathrm{mL}$ of LC-grade water.

To test the extraction recovery of $\mathrm{CA}$ with $\psi($ acetone, $n$-hexane $)=2: 1$ mixture from wet industrial soils, the wet Ind Soil 1 was spiked with CA at level corresponding to the highest CA mass fractions found in industrial soils that were analysed in this work. The soil samples spiked with $400 \mathrm{mg} \mathrm{kg}^{-1}$ of CA were prepared by adding $2.0 \mathrm{~mL}$ of ethanolic $1.0 \mathrm{~g} \mathrm{~L}^{-1} \mathrm{CA}$ solution and $0.5 \mathrm{~mL}$ of acetone to $5 \mathrm{~g}$ of wet soil. The samples were left at room temperature until the solvent evaporated 
$(\approx 24 \mathrm{~h})$ and then were extracted as described for determination of CA in industrial soils. Dry residue of extracts evaporated under a stream of nitrogen was dissolved in $1.0 \mathrm{~mL}$ of $0.01 \mathrm{~mol} \mathrm{~L}^{-1}$ phosphate buffer, $\mathrm{pH}=7.2$ and analysed by HPLC-UV(DAD).

\section{Influence of Sample Matrix on the LC-ToF-MS Determination of Cyanuric Acid}

To test the influence of sample matrix on mass spectrometric response in the LC-ToF-MS determination of $\mathrm{CA}$, the $5 \mathrm{~g}$ air-dried and sieved soil/sediment samples (Forest Soil, Agr Soil, Agr Sed 1, and Agr Sed 2) were ultrasonically extracted with $20 \mathrm{~mL}$ of either methanol or mixture of acetone and $n$-hexane (volume ratio $=2: 1$ ) for $5 \mathrm{~min}$. After centrifugation at $425 \mathrm{~g}$ for $10 \mathrm{~min}$, the supernatant was decanted and the extraction of soil/sediment repeated with a new $10 \mathrm{~mL}$ portion of the same solvent. The extracts were combined and then divided into $6 \mathrm{~mL}$ aliquots so that each aliquot corresponded to $1 \mathrm{~g}$ of soil. The extract aliquots were reduced under a gentle stream of nitrogen to dryness. The residue was reconstituted in $1.0 \mathrm{~mL}$ of aqueous $\mathrm{CA}$ standard solutions of mass concentrations ranging from $0.25 \mathrm{mg} \mathrm{L}^{-1}$ to $2.57 \mathrm{mg} \mathrm{L}^{-1}$. The samples were analysed by LC-ToF-MS immediately after preparation.

\section{RESULTS AND DISCUSSION}

To optimise the HPLC-UV(DAD) conditions for the determination of $\mathrm{CA}$ in soil extracts, the performance of two LC columns of different polarity was compared by analysing CA standard solutions prepared either in LCgrade water or in phosphate buffer $(\mathrm{pH}=7.2)$. One column was a non-polar hydrophobic Hypersil ODS (octadecyl-bonded silica) and the other a less hydrophobic LiChrospher $100 \mathrm{CN}$ (cyano-bonded silica). Both columns were of equal dimensions and particle sizes. The isocratic elution of CA was carried out either with a mixture of acetonitrile and water or with a mixture of acetonitrile and phosphate buffer. The resulting chromatograms are shown in Figure 2. For the determination of CA on Hypersil ODS column, both the mobile phase and the analysed sample had to be buffered at $\mathrm{pH}>7$ in order to avoid the CA peak splitting because of ketoenol tautomerism. ${ }^{1}$ Unlike octadecyl-column, when analysed on the cyano-column and with the use of nonbuffered acetonitrile/water mobile phases, CA dissolved in LC-grade water was detected as a single peak of good shape. With the mobile phase consisting of acetonitrile and water mixture (volume ratio $=5: 95$ ), the efficiency of cyano-column for the determination of CA was comparable to that of the octadecyl-column with the buffered mobile phase (number of theoretical plates $\approx 1000$ ). However, the efficiency of the former column was doubled (number of theoretical plates $\approx 2200$ ) when the

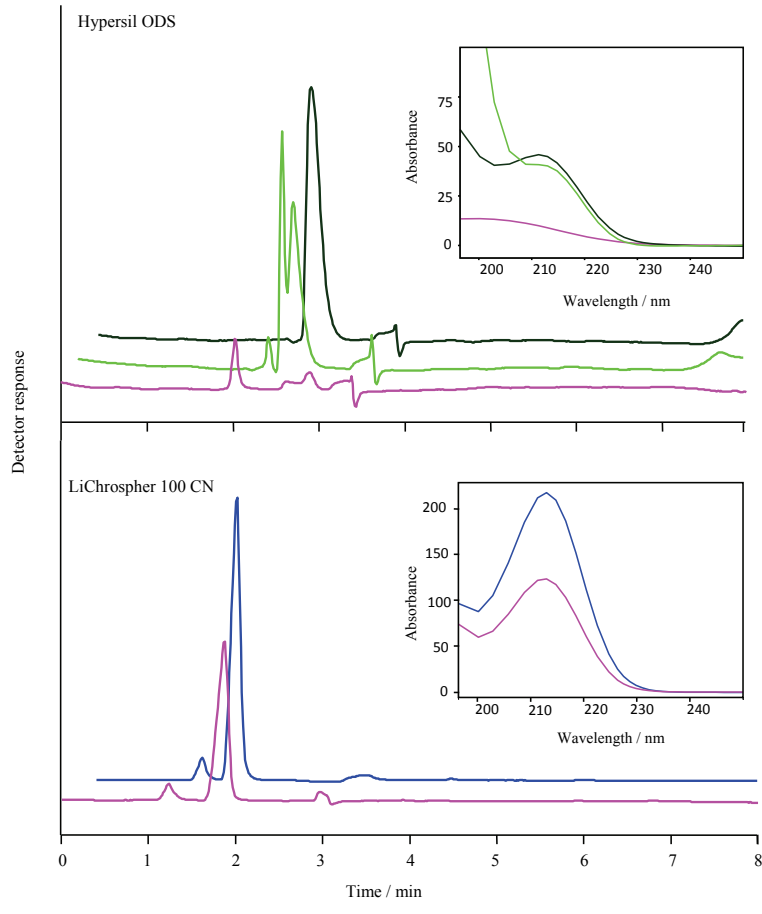

Figure 2. HPLC-UV(DAD) chromatograms $(\lambda=213 \mathrm{~nm})$ and corresponding UV-spectra of CA standard solutions on two columns of different polarity (Hypersil ODS and LiChrospher $100 \mathrm{CN}$ ): $1.0 \mu \mathrm{g} \mathrm{m}^{-1}$ standard solution of CA in phosphate buffer ( $\mathrm{pH}=7.2$ ), mobile phase $\psi($ acetonitrile, phosphate buffer, $\mathrm{pH}=7.2)=5: 95(-) ; 1.0 \mu \mathrm{gL}^{-1}$ standard solution of CA in LC-grade water, mobile phase $\psi($ acetonitrile, phosphate buffer, $\mathrm{pH}=7.2)=5: 95(-) ; 1.0 \mu \mathrm{g} \mathrm{mL}^{-1}$ standard solution of CA in LC-grade water, mobile phase $\psi($ acetonitrile, water $)=$ $5: 95(-) ; 3.4 \mu \mathrm{g} \mathrm{mL}^{-1}$ standard solution of CA LC-grade water, mobile phase $\psi($ acetonitrile, water $)=50: 50(-)$. Injection volume: $100 \mu \mathrm{L}$.

mobile phase consisting of equal proportions of organic solvent and water was used.

The linearity of UV(DAD) response was tested by analysing CA standards in phosphate buffer and LCgrade water on Hypersil ODS and LiChrospher $100 \mathrm{CN}$ column, respectively. For both columns, the detector response was linear at $\mathrm{CA}$ mass concentrations ranging from $0.5 \mu \mathrm{g} \mathrm{mL}^{-1}$ to $4.5 \mu \mathrm{g} \mathrm{mL}^{-1}$ (i.e., from $50 \mathrm{ng}$ to 450 ng of injected CA) with correlation coefficient $r \geq 0.996$. At an injection volume of $100 \mu \mathrm{L}$, the CA detection limit was $0.3 \mu \mathrm{g} \mathrm{mL}^{-1}$, based on a signal to noise ratio of $3: 1$.

The advantage of Hypersil ODS column over the cyano-column was 1 minute longer $\mathrm{CA}$ retention time, which should allow better resolution of CA peak from chromatographic void volume and early-eluting polar interferences that possibly appear in the HPLCUV(DAD) chromatograms of soil extracts. Therefore, this column in isocratic elution mode with the mixture of phosphate buffer $(\mathrm{pH}=7.2)$ and acetonitrile was chosen for quantitating $\mathrm{CA}$ extracted from industrial 
Table 2. Mass fractions of triazine herbicides and CA in industrial soils collected in an agrochemical factory

\begin{tabular}{lrrrr}
\hline \multirow{2}{*}{ Compound } & \multicolumn{4}{c}{ Mass fraction, $w / \mathrm{mg} \mathrm{kg}^{-1} \mathrm{~d} . \mathrm{m}}$. \\
\cline { 2 - 5 } & Ind Soil 1 & Ind Soil 2 & Ind Soil 3 & Ind Soil 4 \\
\hline CA & $<0.50$ & 7.52 & 4.31 & 380 \\
Atrazine & 0.14 & 2.22 & 1.10 & 417 \\
Simazine & 0.08 & 0.08 & 24.98 & 761 \\
Propazine & 0.03 & 0.08 & 3.81 & 1166 \\
Terbuthylazine & $<0.01$ & 0.04 & 0.25 & 315 \\
\hline
\end{tabular}

soils that were long contaminated with triazine herbicides. CA and four triazine herbicides were simultaneously extracted from soils under the same conditions using a mixture of acetone and $n$-hexane (volume ratio $=$ $2: 1)$ as the extracting solvent. This ultrasonic procedure was previously found efficient for extracting chlorotriazine herbicides from different soils. ${ }^{36}$ Atrazine, simazine, propazine, and terbuthylazine were quantified by GC-TSD analysis of industrial soil extracts and their identity was additionally verified by GCITD-MS. The mass fractions of triazine herbicides and CA in four industrial soil samples are presented in Table 2. CA was detected in three of these soils in mass fractions ranging from $4.31 \mathrm{mg} \mathrm{kg}^{-1}$ to $380 \mathrm{mg} \mathrm{kg}^{-1}$ of dry mass (d.m.). The highest herbicide and CA mass fractions were measured in Ind Soil 4 collected closest to a former old plant for the production of herbicides.

The efficiency of the applied ultrasonic procedure for the extraction of CA from industrial soil was tested by analysing wet Ind Soil 1 fortified with CA at a level of $400 \mathrm{mg} \mathrm{kg}^{-1}$. This soil originally contained the lowest atrazine, simazine, and propazine mass fractions of all soils, while terbuthylazine and CA were not detected at all. The recovery of CA from wet Ind Soil 1 was $76 \%$ (average of three determinations) with a relative standard deviation of $6 \%$.

To confirm the identity of CA in industrial soils, soil extracts were analysed by LC-ToF-MS after solvent exchange (acetone/ $n$-hexane mixture with LC-grade water). The analysis was performed using the LiChrospher $100 \mathrm{CN}$ column and the mobile phase consisting of equal proportions of acetonitrile and water, which was also compatible with ESI-MS. Figure 3 compares the chromatograms of CA in Ind Soil 4 extracts analysed by HPLC-UV(DAD) on the Hypersil ODS column and by LC-ToF-MS on the LiChrospher $100 \mathrm{CN}$ column. CA retention time in the applied LC-ToF-MS system was nearly the same as in the HPLC-UV(DAD) system. The mass spectrum showed the signal at $\mathrm{m} / \mathrm{z}$ 128.0092 corresponding to deprotonated CA molecule with elemental formula $\mathrm{C}_{3} \mathrm{H}_{2} \mathrm{~N}_{3} \mathrm{O}_{3}$. The calculated monoisotopic mass of [M-H] $]^{-}$ion was 128.0096 and the mass measurement accuracy was $3.0 \mathrm{ppm}$.

The LC-ToF-MS analysis of CA standards prepared in LC-grade water indicated that chromatographic peak shape was dependent on the sample volume injected. Symmetric and sharp peaks were obtained with injection volumes not exceeding $30 \mu \mathrm{L}$. The injection volumes also affected the linearity of the multichannel plate detector response. To investigate this effect, we compared the calibration curves constructed by injecting either varying volumes $(2 \mu \mathrm{L}$ to $30 \mu \mathrm{L})$ of a 4.59 $\mu \mathrm{g} \mathrm{mL} \mathrm{mL}^{-1} \mathrm{CA}$ standard solution or a fixed volume (20 $\mu \mathrm{L}$ or $30 \mu \mathrm{L}$ ) of the $\mathrm{CA}$ standards of concentrations
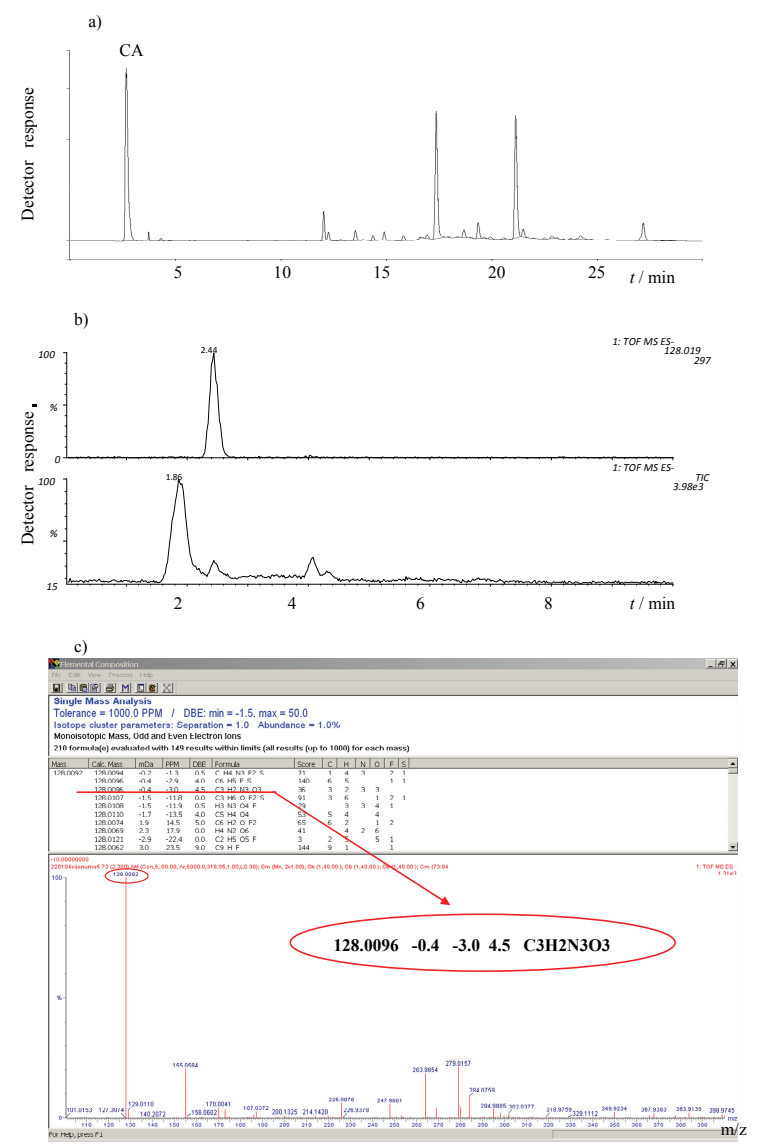

Figure 3. Determination of CA extracted from Ind Soil 4: HPLC-UV(DAD) chromatogram on Hypersil ODS column (a); LC-ToF-MS total ion current chromatogram (bottom) and extracted ion chromatogram for $m / z 128$ (top) on LiChrospher $100 \mathrm{CN}$ (b); identification of CA by LC-ToF-MS - mass spectrum and accurate mass measurement (c). 


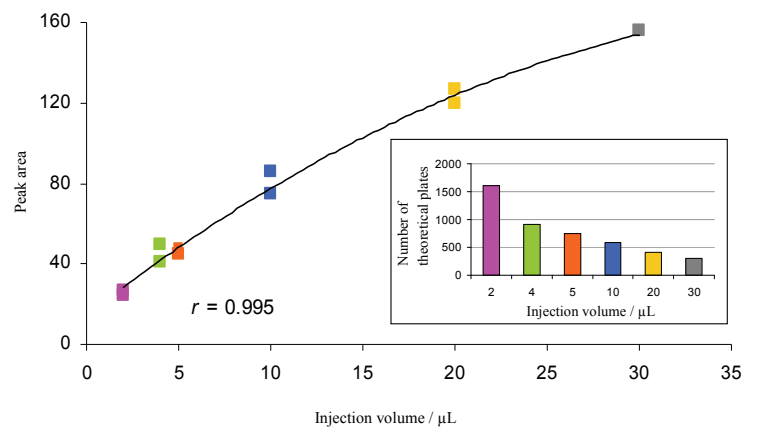

Figure 4. LC-ToF-MS determination of CA: the non-linear calibration curve obtained by injecting varying volumes of a $4.59 \mu \mathrm{g} \mathrm{mL} \mathrm{m}^{-1}$ standard solution of CA in LC-grade water. Effect of injection volume on the number of theoretical plates.

ranging from $0.92 \mu \mathrm{g} \mathrm{mL}^{-1}$ to $4.59 \mu \mathrm{g} \mathrm{mL} \mathrm{mL}^{-1}$. As shown in Figure 4, with the increasing injection volume of the same CA standard solution (injected CA masses ranging from $9 \mathrm{ng}$ to $138 \mathrm{ng}$ ) the number of theoretical plates clearly decreased, which resulted in a calibration curve better fitting to a non-linear second degree polynomial function $(r=0.995)$ than to a linear function $(r=0.987)$. However, when injecting a fixed volume of $20 \mu \mathrm{L}$ or 30 $\mu \mathrm{L}$ of CA standard solutions of varying concentrations, the detector response was linear $(r=0.998)$ in a wider range, i.e., at injected $\mathrm{CA}$ masses ranging from $18 \mathrm{ng}$ to $108 \mathrm{ng}$ and $28 \mathrm{ng}$ to $138 \mathrm{ng}$, respectively. The $20 \mu \mathrm{L}$ injection volume, enabling a CA detection limit of $0.2 \mu \mathrm{g}$ $\mathrm{mL}^{-1}$, was selected as optimum in all further experiments because of the slightly better peak shape and higher peak area compared to those achieved by injecting $30 \mu \mathrm{L}$.

The applicability of the LC-ToF-MS analysis for determining $\mathrm{CA}$ in soil extracts was further tested by spiking acidic surface forest soil (Table 1, Forest Soil) and neutral agricultural subsurface soil (Table 1, Agr Sed 3), differing in organic matter and clay content, with CA at a level of $15.3 \mathrm{mg} \mathrm{kg}^{-1}$ d.m. The efficiency of the acetone $/ n$-hexane mixture in the ultrasonic extraction of CA from soil was compared with the efficiency of the more polar methanol. The extracts were evaporated and dry residue was redissolved in LC-grade water for the LC-ToF-MS analysis on the LiChrosphere 100 $\mathrm{CN}$ column. All CA ion extracted chromatograms were interference-free. The recoveries of CA achieved from two tested soils with two different extraction solvents were significantly different. This emphasized the need to test CA recoveries from each investigated soil type. Eighty percent (RSD $7 \%, n=5)$ of CA was recovered from acidic Forest Soil if extracted with acetone $/ n$-hexane mixture and $67 \%(\mathrm{RSD} 4 \%, n=5)$ if extracted with methanol. On the contrary, methanol was significantly more efficient in extracting CA from neutral $\mathrm{Agr}$ Sed 3 (recovery $111 \%$, RSD $5 \%, n=5$ ) than the less polar acetone $/ n$-hexane mixture (recovery $66 \%$, RSD $9 \%$, $n=5$ ). The detection limit of CA in soil estimated under the optimum extraction conditions was $0.2 \mathrm{mg} \mathrm{kg}^{-1} \mathrm{~d}$.m. Any attempt to analyse the same soil extracts for CA by HPLC-UV(DAD) failed because of the coeluting interferences most likely originating from the soil matrix. The UV detection was obviously insufficiently selective for the determination of $\mathrm{CA}$ without additional purification of these soil extracts, highlighting the advantage of high ion selectivity of the ToF-MS detection system.

One drawback of ESI-MS analysis is that the ionisation process can be susceptible to matrix signal suppression. ${ }^{37}$ The possible soil matrix effect on the ESIToF-MS response to CA was evaluated by analysing blank soil extracts spiked with CA at mass concentrations of $0.25 \mu \mathrm{g} \mathrm{mL}^{-1}, 1.20 \mu \mathrm{g} \mathrm{mL}^{-1}$, and $2.5 \mu \mathrm{g} \mathrm{mL}^{-1}$ and standards of the same concentrations prepared in LC-grade water. These extracts were prepared by ultrasonic extraction of four soils, differing in organic matter content and other pedological properties (Table 1, Forest Soil, Agr Soil, Agr Sed 1, Agr Sed 2). The soils were extracted either with methanol or acetone $/ n$-hexane mixture and the extract aliquots used for spiking corresponded to the extraction of $1 \mathrm{~g}$ of soil. The ratios of CA peak area measured in chromatograms of the spiked soil extracts and of the LC-grade water standard solutions are compared in Table 3. No significant difference was observed in the soil matrix influence on the MS response between methanol and acetone $/ n$-hexane extracts of four different soils. Compared to the standards in LC-grade water, the CA peak area in soil extract chromatograms was reduced by $10 \%$, on average, at the lowest and $5 \%$ at the highest spiked mass concentration level. However, the slopes of calibration lines con-

Table 3. Influence of soil/sediment matrix on ESI-ToF-MS response: ratio of CA peak areas measured in chromatograms of spiked acetone $/ n$-hexane $(\mathrm{A} / \mathrm{H})$ or methanol $(\mathrm{MeOH})$ extracts of blank soils (samples) and in standards prepared in LC-grade water

\begin{tabular}{cccccccc}
\hline & \multicolumn{7}{c}{ Sample to standard peak area ratio } \\
\hline$\gamma(\mathrm{CA}) / \mu \mathrm{g} \mathrm{mL}{ }^{-1}$ & \multicolumn{3}{c}{0.25} & & 1.20 & & 2.57 \\
\hline & $\mathrm{A} / \mathrm{H}$ & $\mathrm{MeOH}$ & $\mathrm{A} / \mathrm{H}$ & $\mathrm{MeOH}$ & $\mathrm{A} / \mathrm{H}$ & $\mathrm{MeOH}$ \\
\cline { 2 - 8 } Forest Soil & 0.84 & 0.87 & 0.93 & 0.96 & 0.90 & 0.92 \\
Agr Soil & 0.93 & 0.89 & 0.93 & 0.91 & 0.96 & 1.00 \\
Agr Sed 1 & 0.90 & 0.95 & 1.00 & 0.92 & 0.94 & 0.99 \\
Agr Sed 2 & 0.90 & 0.88 & 0.89 & 0.93 & 0.99 & 0.88 \\
\hline
\end{tabular}


structed by the analysis of standards prepared in LCgrade water and in the four sets of blank soil extracts at the three tested CA concentration levels showed no significant difference. The correlation coefficients were higher than 0.999 for all calibration lines. Accordingly, for the determination of $\mathrm{CA}$ in extracts of $1 \mathrm{~g}$ of soil, calibration standards can be prepared in water due to the non-significant influence of soil matrix on the MS response. However, the possibility of negative effects of matrix components on the quantitation of $\mathrm{CA}$ in extracts prepared by extraction of soil mass higher than $1 \mathrm{~g}$ should not be disregarded. It is therefore advisable to use the matrix-matched standards or, even better, an appropriate internal standard (e.g. the isotope-labelled CA), which will be affected by the ion suppression to a comparable extent as the target analyte. ${ }^{37}$

\section{CONCLUSION}

The LiChrospher $100 \mathrm{CN}$ column proved suitable for determining CA dissolved in pure water and along with the use of the non-buffered mobile phase, met the conditions required for the LC-ToF-MS determination of CA detected in negative ESI mode. In both methanol and acetone $/ n$-hexane extracts prepared by extracting $1 \mathrm{~g}$ of different soils, the effect of soil matrix on suppression of CA ionisation was not significant. The method provided highly selective determination of $\mathrm{CA}$ in soil extracts due to high ion detection selectivity, minimising the interferences of possible co-eluting species, and the unambiguous identification of target analyte by accurate mass measurements of deprotonated molecule. However, additional efforts are needed to improve the extraction of CA from different soils and to achieve equally high recoveries regardless of the soil type. The high mass fractions of CA found in industrial soils indicate that this potentially hazardous compound has to be monitored not only in water but also in the soil environment.

Acknowledgements. This study was supported by the Ministry of Science, Education, and Sports of the Republic of Croatia through the Project 022-0222882-2896 "Organic micropollutants in the environment - distribution, interactions, human exposure".

\section{REFERENCES}

1. R. Cantú, O. Evans, F. K. Kawahara, J. A. Shoemaker, and A. P. Dufour, Anal. Chem. 72 (2000) 5820-5828.

2. J. Wojtowicz, Cyanuric and Isocyanuric Acids, Kirk-Othmer Encyclopedia of Chemical Technology. Copyright (C) 2001 by John Wiley \& Sons, Inc. Published Online: 18 June 2004.

3. L. P.Wacket, M. J. Sadowsky, B. Martinez, and N. Shapir, Appl. Microbiol. Biotechnol. 58 (2002) 39-45.

4. F. Sun, W. Ma, L. Xu, Y. Zhu, L. Liu, C. Peng, L. Wang, H. Kuang, and C. Xu, TrAC, Trends Anal. Chem. 29 (2010) 1239-1249.
5. C. A. Brown, K. S. Jeong. R. H. Poppenga, B. Puschner, D. M. Miller, A. E. Ellis, K. I. Kang, S. Sum, A. M. Cistola, and S. A. Brown, J. Vet. Diagn. Invest. 19 (2007) 525-531.

6. B. Puschner, R. H. Poppenga, L. J. Lowenstine, M. S. Filigenzi, and P. A. Pesavento, J. Vet. Diagn. Invest. 19 (2007) 616-624.

7. E. Topp, Biol. Fertil. Soils 33 (2001) 529-534.

8. D. Smith, S. Alvey, and D. E. Crowley, FEMS Microbiol. Ecol. 53 (2005) 265-273.

9. N. Udiković Kolić, D. Hršak, A. Begonja Kolar, I. Petrić, S. Stipičević, G. Soulas, and F. Martin-Laurent, Int. Biodeter. Biodegr. 60 (2007) 299-307.

10. K. Satsuma, Chemosphere 77 (2009) 590-596.

11. M. S. Lai, J. N. Jensen, and A. S. Weber, Wat. Environ. Res. 67 (1995) 340-346.

12. V. Héquet, C. Gonzalez, and P. Le Cloirec, Wat. Res. 35 (2001) 4253-4260.

13. C. Y. Chan, S. Tao, R. Dawson, and P. K. Wong, Environ. Pollut. 131 (2004) 45-54.

14. J. Y. Shin and M. A. Cheney, Environ. Toxicol. Chem. 24 (2005)1353-1360.

15. R. Cantú, O. Evans, and M. L. Magnuson, Chromatographia 53 (2001) 454-456.

16. R. Cantú, O. Evans, F. K. Kawahara, L. J. Wymer, and A. P. Dufour, Anal. Chem. 73 (2001) 3358-3364.

17. S. Ehling, S. Tefera, I. P. Ho, Food Addit. Contam. 24 (2007) 1319-1325.

18. C. Yu, L. Zhu, J. Xiao, H. Tang, G. Guo, Q. Zeng, and X. Wang, Food Control 20 (2008) 205-208.

19. R. Muñiz-Valencia, S. G. Ceballos-Magaña, D. RosalesMartinez, R. Gonzalo-Lumbreras, A. Santos-Montes, A. CubedoFernandez-Trapiella, and R. C. Izquierdo-Hornillos, Anal. Bioanal. Chem. 392 (2008) 523-531.

20. D. W. Hamilton and P. A. O’Neal, J. Sep. Sci. 26 (2003) 510-514.

21. K. Patel and K. Jones, J. Chromatogr. B 853 (2007) 360-363.

22. C. Han, Y. Zhou, B. Xia, Z. Zhu, C. Liu, and Y. Shen, J. Sep. Sci. 34 (2011) 371-375.

23. C. Han, C. Liu, Y. Zhou, B. Xia, Z. Zhu, X. Lei, and Y. Shen, Food Chem. 127 (2011) 875-879.

24. C. M. Karbiwnyk, W. C. Andersen, S. B. Turnipseed, J. M. Storey, M. R. Madson, K. E. Miller, C. M. Gieseker, R. A. Miller, N. G. Rummel, and R. Reimschuessel, Anal. Chim. Acta 637 (2009) 101-111.

25. M. S. Filigenzi, B. Puschner, L. S. Aston, and R. H. Poppenga, J. Agric. Food Chem. 56 (2008) 7593-7599.

26. M. Zhang, S. Li, C. Yu, G. Liu, J. Jia, C. Lu, J. He, Y. Ma, J. Zhu, and C. Yu, J. Chromatogr. B 878 (2010) 758-762.

27. Y. C. Fiamegos, C. N. Konidari, C. D. Stalikas, Anal. Chem. 75 (2003) 4034-4042.

28. H. P. O. Tang, S. S. L. Lai, A. Y. H. Lai, and W. O. Lee, Chromatographia 70 (2009) 1405-1410.

29. H. Miao, S. Fan, Y-N. Wu, L. Zhang, P-P. Zhou, J-G. Li, H-J. Chen, and Y-F. Zhao, Biomed. Environ. Sci. 22 (2009) 87-94.

30. M. L. Magnuson, C. A. Kelty, and R. Cantú, J. Am. Soc. Mass Spectrom. 12 (2001) 1085-1091.

31. J. A. Campbell, D. S. Wunschel, and C. E. Petersen, Anal. Lett. 40 (2007) 3107-3118.

32. L. Vaclavik, J. Rosmus, B. Popping, and J. Hajslova, J. Chromatogr. A 1217 (2010) 4204-4211.

33. B. Liu, M. Lin, and H. Li, Sens. Instrumen. Food Qual. 4 (2010) 13-19

34. S. Lacorte and A. R. Fernandez-Alba, Mass Spectrom. Rev. 25 (2006) 866-880.

35. F. Hernández, J. V. Sancho, M. Ibáñez, and S. Grimalt, $\operatorname{Tr} A C$, Trends Anal. Chem. 27 (2008) 862-872.

36. S. Stipičević, S. Fingler, L. Zupančič-Kralj, and V. Drevenkar, J. Sep. Sci. 26 (2003) 1237-1246.

37. J-P. Antignac, K. de Wasch, F. Monteau, H. De Brabander, F. Andre, and B. Le Bizec, Anal. Chim. Acta 529 (2005) 129-136. 